\title{
LASER-ASSISTED DEPOSITION OF TRANSITION METAL COATINGS ON GRAPHITE
}

\author{
Deepak Rajput, Lino Costa, Kathleen Lansford, George M. Murray \\ and William H. Hofmeister
}

Center for Laser Applications, 411 B H Goethert Parkway, University of Tennessee Space Institute, Tullahoma, TN 37388-9700, USA

Received: February 14, 2018

\begin{abstract}
This paper reports the deposition of transition metal coatings on graphite by laser melting a pre-placed layer of powder particles using a continuous wave (CW) laser. Titanium, zirconium, and niobium coatings were successfully deposited on semiconductor grade graphite plates using the laser induced surface improvement (LISI) approach. The coatings produced were characterized using scanning electron microscope, energy dispersive spectrometry, X-ray diffraction, microhardness testing, and secondary ion mass spectrometry. Results show the formation of crack-free and dense transition metal coatings and the presence of carbide phases at the coating-graphite interface.
\end{abstract}

\section{INTRODUCTION}

Graphite, one of the three polymorphic forms of carbon, is an excellent structural material due to its exceptional chemical and physicomechanical properties [1-5]. One of the key properties of graphite is its fairly high strength, which increases sharply with temperature. In fact, it has been reported that at $2500^{\circ} \mathrm{C}$ graphite is twice as strong as at room temperature [6]. However, graphite and other carbon materials suffer low resistance to oxidation at high temperatures and low resistance to abrasive wear and erosion, which severely limit their use as structural materials at elevated temperatures [1-6]. Improvement of graphite's high temperature oxidation resistance has remained a subject study since the 1950 's. Early work on surface coating graphite was based on diffusion, plasma, and metal condensation techniques involving one or more steps [7-13], photochemical vapor deposition [14], thermal spraying [15-17], physical vapor deposition [18], chemical vapor deposition $[19,20]$, solid-vapor reaction process [4], powder immersion reaction assisted coating (PIRAC) [21], and more recently laser melting pre-placed powder using a high power pulsed laser [22-24]. Laser-assisted synthesis of surface coatings has been successfully demonstrated for many materials and is used to solve numerous surface performance issues. In general, laser alloying and laser cladding carried out on metals will produce fully dense, metallurgically bonded surface coatings with a minimal heat affected zone $[25,26]$. Laser processing can be easily limited to a region of interest. Resulting microstructures range from fully melted and rapidly solidified alloys to cermet type microstructures of ceramic particles in a metallic matrix, as demonstrated with the laser induced surface improvement (LISI) method [27,28].

Laser-assisted synthesis of surface coatings on graphite presents unique challenges of its own. For one, graphite will sublimate if exposed directly to intense laser radiation. This is prevented by covering the graphite surface with an optically thick layer of the powder materials that go into forming the coat-

Corresponding author: D. Rajput, e-mail: drajput@vols.utk.edu 
ing. With LISI, this is accomplished with the help of an organic binder that ensures both good adhesion to and uniform coverage of the base material by the powder materials [29]. In addition, liquid metals do not generally wet graphite and form stable chemical bonds necessary to make adherent coatings. Wetting in metal - graphite systems generally occurs when reactions at the liquid - solid interface produce a third interfacial compound that is better wetted than the graphite substrate [30]. Thus, making a well-adhered surface coating on graphite is very challenging, and it strongly depends on the coating elements and their ability to form chemical bonds with carbon.

The transition metals have outstanding ability to combine strongly with carbon due to their partlyfilled $d$ orbitals in their valence shells, and form strong covalent bonds. The more the defectiveness in the $\mathrm{d}$ or $\mathrm{f}$ electron shells, the stronger the carbide forming ability of the transition metal. The carbide forming ability of the transition metals can thus be summarized as $\mathrm{Fe}<\mathrm{Mn}<\mathrm{Cr}<\mathrm{Mo}<\mathrm{W}<\mathrm{V}<\mathrm{Nb}<\mathrm{Ta}$ $<\mathrm{Ti}<\mathrm{Zr}<\mathrm{Hf}$ [31]. In the present study we have deposited titanium, zirconium, and niobium coatings on graphite substrate by laser melting their preplaced elemental powders in controlled atmosphere.

\section{MATERIALS AND METHODS}

The precursor mixtures for titanium, niobium, and zirconium were made by mixing their elemental powders with LISI i-8 binder $^{1}$ (proprietary formulation of Warren Paint and Color Company, Nashville, $\mathrm{TN})$. The precursor mixture thus prepared was sprayed on $6 \mathrm{~mm}$ thick graphite plates with an air spray gun (Crescendo $₫$, Model 175 by Badger Airbrush Co., IL), and then dried under a heat lamp for several hours before laser processing. LISI binder has two functions: 1) to provide sufficient fluidity to the precursor mixture for spraying so that uniform precursor thickness is obtained, and 2) to bind the metal precursor powder particles together and to the substrate once the precursor coating has dried in order to prevent flaking during sample handling. Usually a series of trials is first conducted to find the least amount of binder required to get uniform thickness precursor coating. The amount of binder added to form the precursor mixture depends on the powder particle size and is generally found to have an inverse relationship. The precursor coating thickness is measured before laser processing us-
Table 1. Details of metal powder particles used to make the precursor coatings.

\begin{tabular}{llll}
\hline Metal & $\begin{array}{l}\text { Particle } \\
\text { size } \\
(\mu \mathrm{m})\end{array}$ & $\begin{array}{l}\text { Binder } \\
(\text { weight \%) }\end{array}$ & $\begin{array}{l}\text { Precursor } \\
\text { layer } \\
\text { Thickness } \\
(\mu \mathrm{m})\end{array}$ \\
\hline $\mathrm{Ti}$ & $<44$ & 60 & 75 \\
$\mathrm{Zr}$ & $2-5$ & 10 & 125 \\
$\mathrm{Nb}$ & $<10$ & 33 & 125 \\
\hline
\end{tabular}

Table 2. Physical properties of the semiconductor grade graphite plates used in the experiments.

\begin{tabular}{ll}
\hline Property & Value \\
\hline Particle Size $(\mu \mathrm{m})$ & 5 \\
Coefficient of thermal & 7.9 \\
expansion $\left(\mu \mathrm{m} / \mathrm{m}^{\circ} \mathrm{C}\right)$ & \\
Apparent density & 1.73 \\
Thermal Conductivity $($ Watts $/ \mathrm{mK})$ & 85 \\
Hardness $(\mathrm{SSH})$ & 72 \\
\hline
\end{tabular}

ing a MEGA-CHECK Pocket FN coating thickness gauge (LIST-MAGNETIK GmbH, Germany). Details of precursor materials and precursor coatings are shown in Table 1. The graphite plates used were semiconductor grade (Poco Graphite, Inc.) and were polished (800-grit through 2400-grit) with silicon carbide paper to give a smooth surface finish and dried for several hours before spraying precursor mixtures on them. The physical properties of the graphite plates are shown in Table 2.

Experiments were performed in a water-cooled controlled-atmosphere vacuum chamber integrated with an induction heating element for simultaneous substrate heating and laser processing in an inert atmosphere, as shown in Fig. 1. The processing was done in 4 steps: (i) substrate preheating in vacuum, (ii) chamber purging with argon, (iii) laser processing in argon atmosphere, and (iv) slow-andcontrolled substrate cooling after laser processing. In the first step, the precursor coated graphite substrate is placed on a pan-shaped copper pipe based induction coil connected to a high voltage power supply for preheating. Alumina rods placed between the induction coil and the graphite substrate prevent short-circuiting of the induction coils by the electrically conductive graphite substrate. The tem-

${ }^{1} \mathrm{LISI}$ binder is less than 0.7 weight \% solid and it mostly contains chlorine, fluorine, potassium, and sodium. 


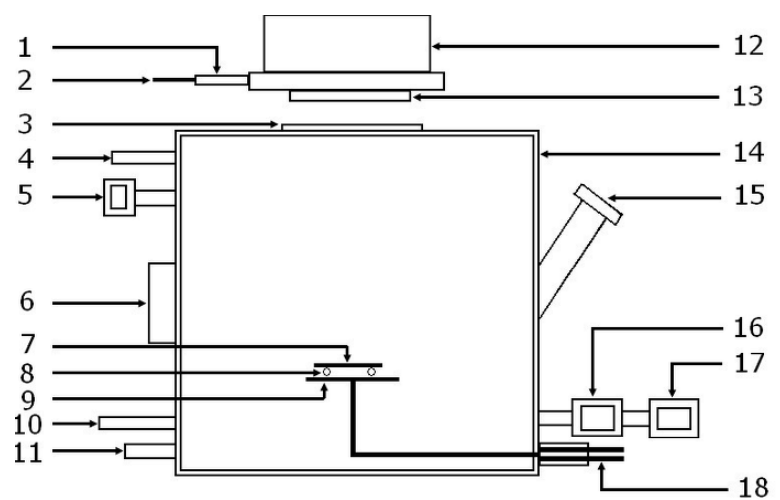

Fig. 1. Schematics of the setup used for laser deposition. 1) beam expander, 2) optical fiber that delivers the laser beam 3) laser entry port, 4) argon feedthrough, 5) vacuum throttle valve, 6) view port, 7) graphite substrate, 8) alumina rods, 9) water-cooled copper induction coil heating element, 10) MKS baratron pressure transducer, 11) thermocouple vacuum gauge, 12) HurryScan 30,13 ) F-theta lens, 14) water-cooled vacuum chamber, 15) view port, 16) turbo pump, 17) mechanical pump, 18) RF power supply.

perature of the graphite surface reaches $\sim 800^{\circ} \mathrm{C}$ during induction heating (as observed using optical pyrometry) which is also effective in burning off the majority of the binder added to the precursor mixture. In the second step, induction heating was continued in argon atmosphere, which heats the chamber walls releasing residual moisture, followed by a chamber purge to remove water vapor and binder residue produced during substrate preheating. The third step was laser processing of preheated precursor-coated-graphite substrate in argon atmosphere maintained at 300 torr below the room pressure. After laser processing the graphite substrate was cooled slowly as the fourth and the final step of processing.

The laser used to melt the precursor metal powders was a 1 kW YLR-1000 (IPG Photonics Corporation) direct diode pumped fiber continuous wave (CW) laser of $1075 \pm 5 \mathrm{~nm}$ wavelength. The laser beam profile was determined to be near-Gaussian [32]. An overhead assembly of galvanometer scan mirrors (ScanLabs HurryScan30) and an F-theta lens, located outside the vacuum chamber, was used to raster the laser beam over the precursor-coated graphite substrate, placed inside the vacuum chamber, and form the metal coatings. A series of trials was conducted, in which different combinations of laser power, scanning speed, laser-beam overlap, and laser diameter were tested to identify optimum conditions for preparing dense metal coatings without causing the graphite to sublimate. The optimized laser processing conditions used finally for preparing the coatings are shown in Table 3.

SEM analysis was done on a Hitachi S4200 Field Emission Scanning Electron Microscope to analyze the coating structure at high magnifications. X-ray diffraction analyses of the interface and the coatings were done on a Philips X'pert system with $\mathrm{Cu}$ $K \alpha$ radiation of wavelength $1.5406 \AA$ maintained at $40 \mathrm{kV}$ and $45 \mathrm{~mA}$. The coating-graphite interface samples for $\mathrm{X}$-ray diffraction analyses were made by gluing the coating side on a glass slide and polishing the graphite side on a polishing wheel at low speed settings till the interface was revealed. Hardness measurements of each coating were taken on a LECO LM 300AT microhardness tester, integrated with LECO AMH32 software, under a load of 25 gramforce and dwell time of 15 seconds using Knoop's indenter. The niobium coating in as received and slightly polished condition was also characterized on a Millbrook MiniSIMS secondary ion mass spectrometer (SIMS) using a beam of $6 \mathrm{keV}$ gallium ions $\left(\mathrm{Ga}^{+}\right)$as the probe. $5 \mathrm{~mm} \times 5 \mathrm{~mm}$ test samples from the niobium coating were cut, ultrasound cleaned in acetone and then rinsed in isopropyl alcohol before the SIMS analysis. Caution was practiced during sample preparation to ensure no water came in contact with the specimen; slightly polished niobium coating samples were prepared by hand polishing the coating surface with an emery paper.

Table 3. Optimum laser processing conditions for each coating.

\begin{tabular}{|c|c|c|c|c|c|}
\hline Coating & $\begin{array}{l}\text { Laser power } \\
\text { (W) }\end{array}$ & $\begin{array}{l}\text { Laser diameter } \\
(\mathrm{mm})\end{array}$ & $\begin{array}{l}\text { Laser intensity } \\
\left(\mathrm{W} / \mathrm{mm}^{2}\right)\end{array}$ & $\begin{array}{l}\text { Scan speed } \\
(\mathrm{m} / \mathrm{s})\end{array}$ & $\begin{array}{l}\text { Overlap } \\
(\%)\end{array}$ \\
\hline $\mathrm{Ti}$ & 235 & 1.28 & 183 & 5 & 86 \\
\hline $\mathrm{Zr}$ & 290 & 0.81 & 563 & 5 & 78 \\
\hline $\mathrm{Nb}$ & 350 & 0.93 & 516 & 5 & 81 \\
\hline
\end{tabular}




\section{RESULTS}

\subsection{Characterization of titanium coating}

Fig. 2 shows the SEM micrograph of the cross-section of the titanium coating on graphite. It shows that the titanium coating is fully dense, crack-free, and around $50 \mu \mathrm{m}$ thick achieving approximately $67 \%$ densification. The coating-graphite interface is around $1 \mathrm{~mm}$ thick and it is mainly composed of titanium carbide as shown by the XRD analysis of the interface in Fig. 3. The interface diffractogram also shows the presence of carbon along with titanium carbide, carbon that comes from the retained graphite that could not be completely removed from the interface during specimen preparation. XRD of the coating surface shows the presence of titanium and titanium oxide $\left(\mathrm{Ti}_{3} \mathrm{O}_{5}\right)$. The formation of titanium oxide can be attributed to the oxidation of titanium during laser processing due to retained oxygen in the processing vacuum chamber or the native oxide of the titanium powder or oxides in the LISI binder. The Knoop's hardness of the titanium coating thus produced was found to be in the range 400-650 HK, which is a sign that the coating is composed of interstitial solid solution strengthened titanium (with carbon) and titanium oxides.

\subsection{Characterization of zirconium coating}

Fig. 4A shows the SEM micrograph of the transverse cross-section of the zirconium coating on graphite, which shows that the coating is fully dense,
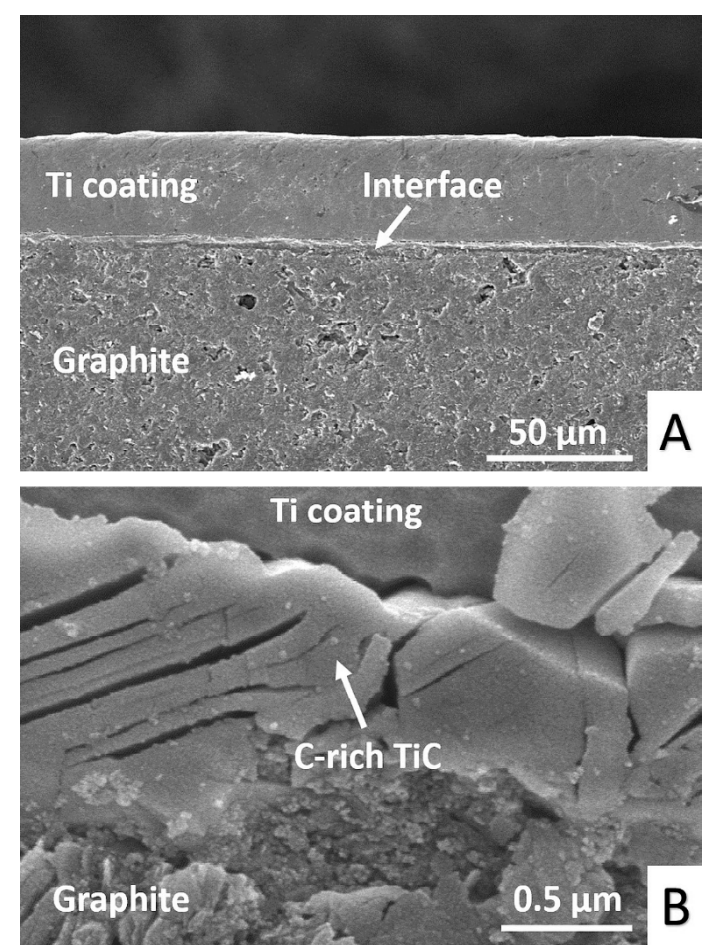

Fig. 2. SEM micrographs of the titanium coating on graphite etched with $100 \mathrm{ml} \mathrm{H}_{2} \mathrm{O}+2 \mathrm{ml} \mathrm{HF}+5 \mathrm{ml}$ $\mathrm{H}_{2} \mathrm{O}_{2}$ for 10 seconds to expose carbides: (A) Fully dense and crack-free Ti deposit, and (B) the coating-graphite interface composed of C-rich TiC.

free of cracks, and around $100 \mu \mathrm{m}$ thick achieving approximately $80 \%$ densification, whereas the coating-graphite interface is around $2 \mu \mathrm{m}$ thick. However, some zirconium coatings were found to have hairline delamination and cracks at the interface as seen in Figure 4B, which can be a sign of residual

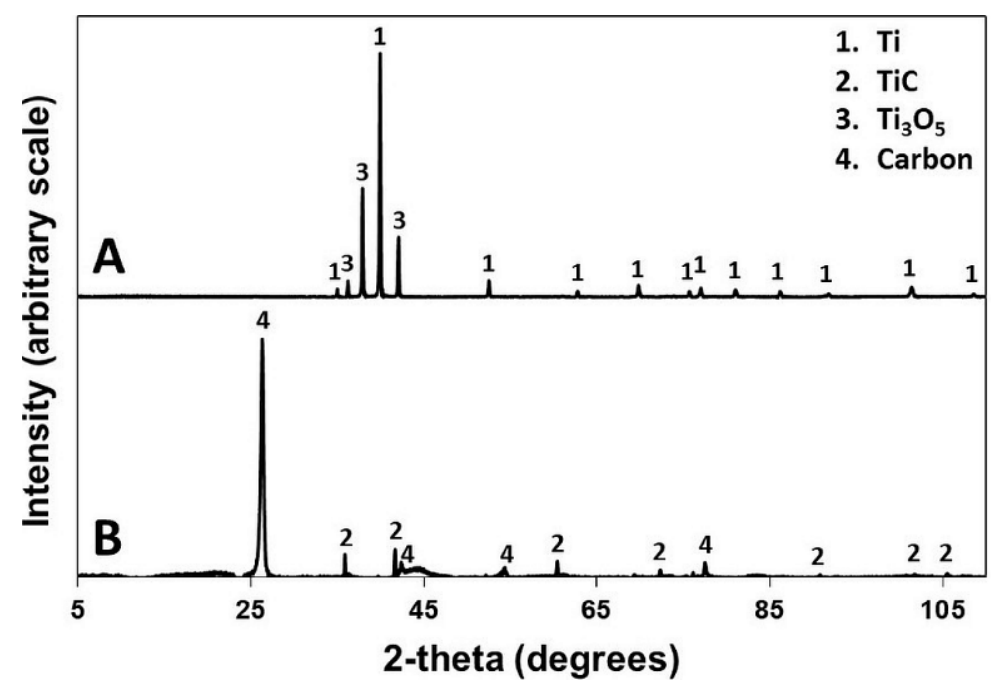

Fig. 3. X-ray diffractograms of the titanium coating surface (A) and the coating-graphite interface (B). The coating surface mostly contains titanium and titanium oxide, whereas the interface is composed of titanium carbide. 

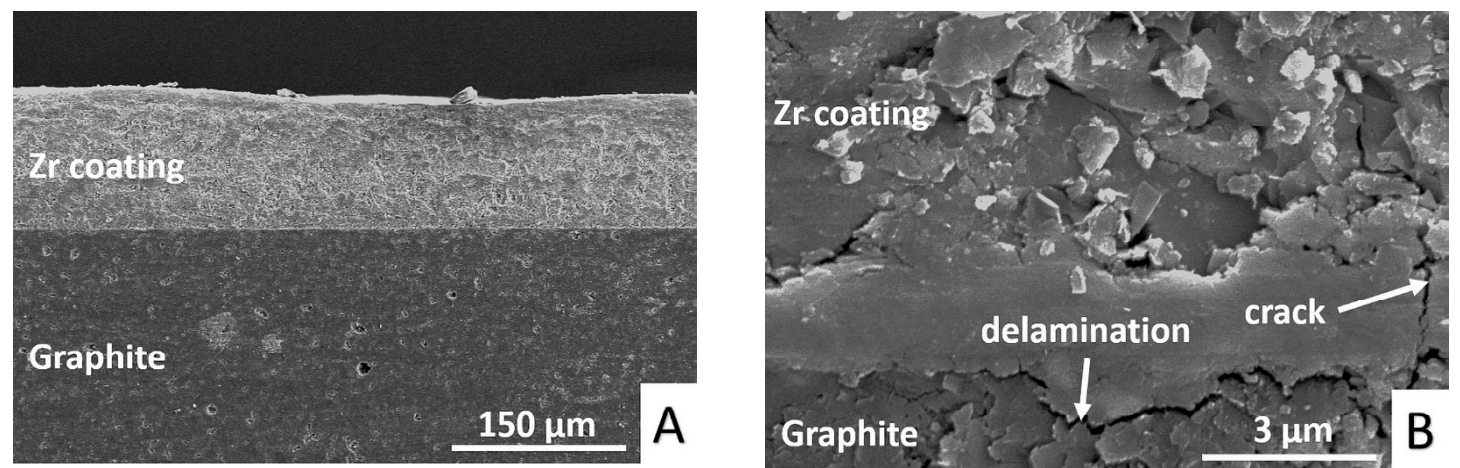

Fig. 4. SEM micrographs of the zirconium coating on graphite etched with $80 \mathrm{ml} \mathrm{H}_{2} \mathrm{O}+20 \mathrm{ml} \mathrm{HF}+1 \mathrm{ml}$ $\mathrm{HNO}_{3}$ for 2 seconds: (A) fully dense $\mathrm{Zr}$ deposit, and (B) the coating-graphite interface. A hairline delamination and crack at the interface can also be seen at high magnification.

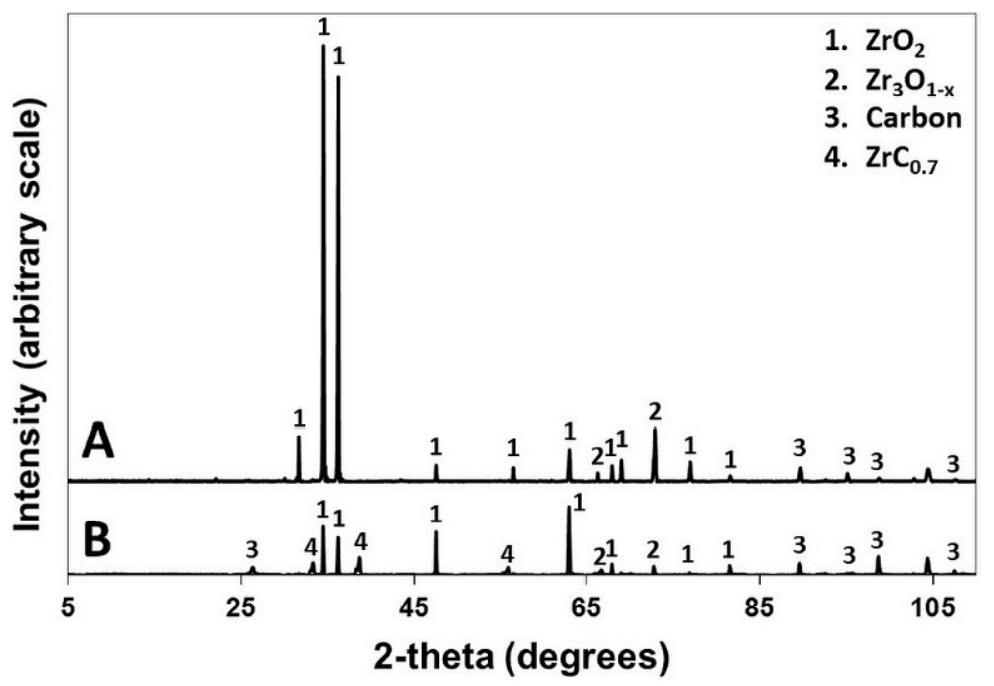

Fig. 5. X-ray diffractograms of the zirconium coating surface $(A)$ and the coating-graphite interface (B). The coating surface mostly contains zirconium oxides, whereas the interface is composed of zirconium oxides and zirconium carbide.
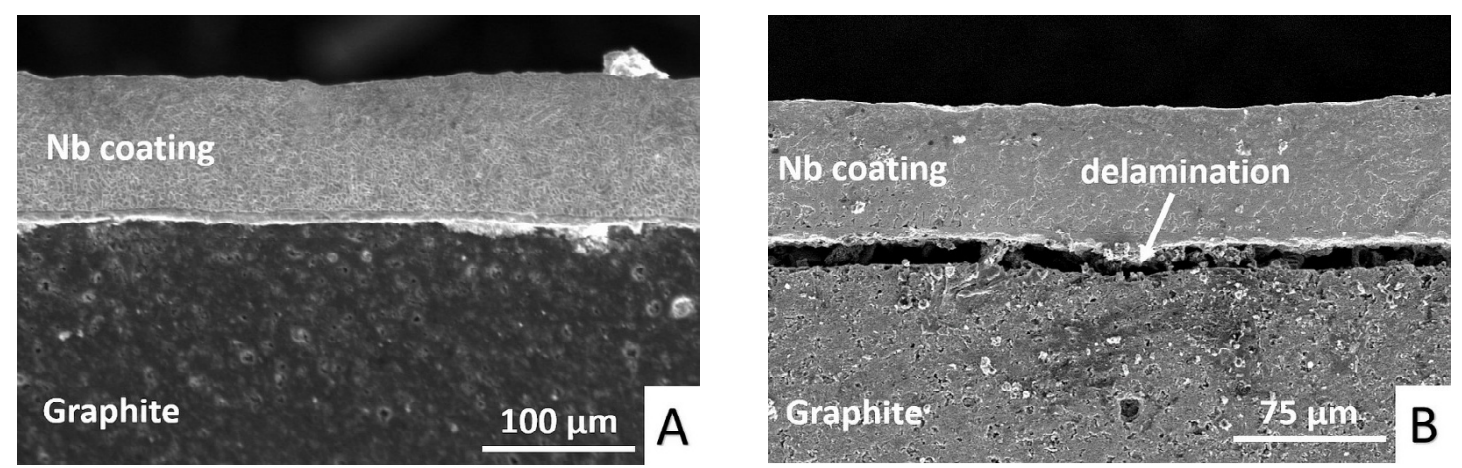

Fig. 6. SEM micrograph of the niobium coating on graphite etched with $50 \mathrm{ml} \mathrm{HNO}_{3}+30 \mathrm{~g} \mathrm{NH}_{4} \mathrm{HF}_{2}+20 \mathrm{ml}$ $\mathrm{H}_{2} \mathrm{O}$ for 15 seconds. The coating is fully dense and crack free (A), and delaminated in some locations during SEM sample preparation (B). The coating fully detached as a single solid sheet during sample preparation for interface XRD analysis.

stresses at the interface. X-ray diffractogram of the zirconium coating surface, Fig. $5 \mathrm{~A}$, shows the presence of various zirconium oxides at the coating surface, which can again be attributed to the oxidation of zirconium during laser processing due to traces of oxygen in the processing chamber, in the LISI binder or in the starting zirconium powder. Zirconium in powder form is known to be highly flammable, hence the small 2-5 $\mu \mathrm{m}$ particles of zirconium used as the starting material oxidize very easily even in the presence of trace amounts of oxygen. In fact, zirconium oxides were also found to be present at 


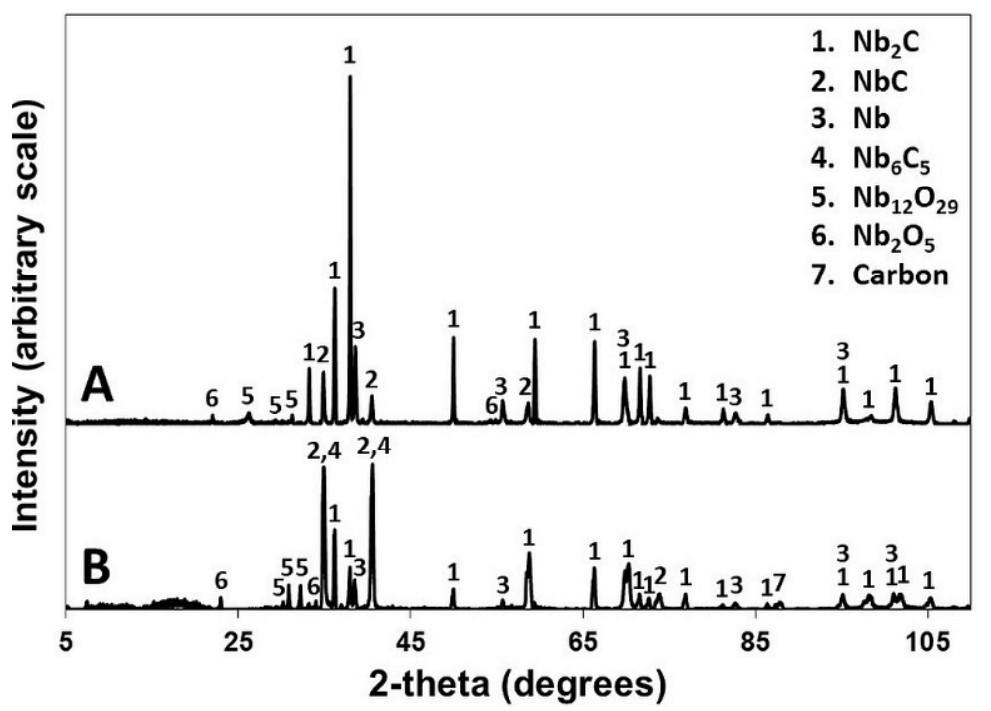

Fig. 7. X-ray diffractograms of the niobium coating surface (A) and the coating-graphite interface (B). The coating surface mostly contains niobium rich carbides and niobium oxides, whereas the interface is composed of carbon rich niobium carbides and niobium oxides.

the coating interface as revealed by the interface $X$ ray diffractogram shown in Fig. 5B. Peaks of zirconium were not seen either at the coating surface or at the interface, however, zirconium carbide $\left(\mathrm{ZrC}_{0.7}\right)$ peaks were seen at the coating interface, which indicates that zirconium reacts with carbon to form zirconium carbide at the interface. The microhardness of the zirconium coating was found to be around $775 \mathrm{HK}$, which can be attributed to the combination of interstitial solid solution strengthened zirconium and the presence of various zirconium oxides and carbides.

\subsection{Characterization of niobium coating}

SEM micrograph of the transverse cross-section of the niobium coating, Fig. 6A, shows that the coating is fully dense, crack-free, and around $100 \mu \mathrm{m}$ thick achieving $80 \%$ densification. The coatinggraphite interface was found to be around 1-2 $\mu \mathrm{m}$ thick. X-ray diffractogram of the niobium coating surface and interface is shown in Fig. 7. Fig. 7A shows that the surface of the niobium coating mostly contains niobium-rich carbide phase $\mathrm{Nb}_{2} \mathrm{C}$. Other phases present at the coating surface are other niobium carbides ( $\mathrm{NbC}$ and $\mathrm{Nb}_{6} \mathrm{C}_{5}$ ), niobium, and niobium oxides $\left(\mathrm{Nb}_{2} \mathrm{O}_{5}\right.$ and $\left.\mathrm{Nb}_{12} \mathrm{O}_{29}\right)$. While preparing the specimen for interface XRD analysis, the coating detached from the graphite surface as a single solid sheet, which indicates that the coating-graphite adhesion was weak. The interface diffractogram, Fig. 7B, shows strong presence of $\mathrm{NbC}$ and $\mathrm{Nb}_{6} \mathrm{C}_{5}$ phases. Although $\mathrm{Nb}_{2} \mathrm{C}$ and niobium are also present at the interface, their peaks become more intense towards the surface. The interface also contains niobium oxides $\mathrm{Nb}_{2} \mathrm{O}_{5}$ and $\mathrm{Nb}_{12} \mathrm{O}_{29}$. The formation of niobium oxides at the interface and the coating can be attributed to oxygen supplied either by the LISI binder or by its traces present in the processing chamber or the starting niobium powder. The hardness of the niobium coating was found to be in the range 620-1220 HK. This large variation in the hardness values can be attributed to the dispersion of different microconstituents (carbides, oxides, and niobium) in the coating as seen in the X-ray diffractograms.

The niobium coating was also characterized with a secondary ion mass spectrometer (SIMS) in asreceived and slightly polished conditions to investigate the presence of binder in the coating which was added to the precursor mixture. LISI binder is a water-based thixotropic suspension of light elements like sodium, magnesium, potassium and calcium; however, its exact chemical composition is not available due to its proprietary nature. SIMS is a very sensitive surface analysis technique, which uses a beam of charged atoms or molecules as the probe usually operated in $1-25 \mathrm{keV}$ range ( $6 \mathrm{keV} \mathrm{Ga}+$ ions in the present study). The SIMS quadruple mass spectrometer is more sensitive towards lighter elements like the ones in the LISI binder and thus more appropriate for analyzing surface elements of the LISI coatings compared to EDX. The mass spectra of as-received and slightly-polished niobium coatings are shown in Fig. 8, which show the presence 


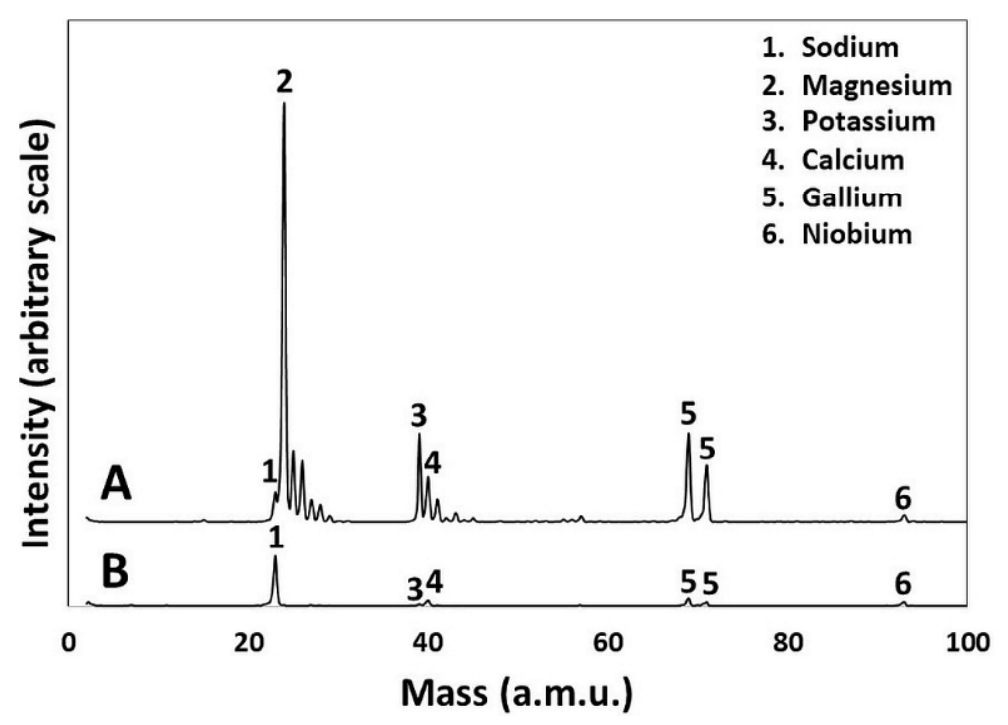

Fig. 8. SIMS positive ion mass spectrum of the niobium coating surface: (A) as-received, (B) slightly polished. Note that the intensity of slightly polished specimen is not normalized in order to enhance it.

of sodium, magnesium, potassium, and calcium in both the cases in addition to gallium and niobium. However, the intensities of lighter elements drop drastically for slightly-polished coating, which confirms that the LISI binder elements are only present at the coating surface. From the SIMS analysis, it can be deduced that the LISI binder forms a thin layer of slag during laser processing atop the coating surface.

\section{DISCUSSION: COATING FORMATION AND INTEGRITY}

Since graphite does not form a direct chemical bond with the metal coating, the coating-graphite adhesion depends solely on the interfacial carbide layer formed during coating deposition [33]. Formation of transition metal coatings on graphite by LISI process is attributed to laser melting, caused by the absorption of laser energy by the metal powders in the precursor coating, and reactive wetting between the liquid metal and graphite, which leads to the formation of a metal carbide interface. However, depositing surface coatings on graphite by laser processing can be very challenging. Unlike most common laser alloying and laser cladding situations, where laser melting of the substrate plays an important part in forming an adherent coating, graphite does not exist in liquid state at room pressure. Instead, graphite sublimates when exposed to laser radiation. Given graphite's high optical absorbance, this phase transformation is easily initiated under the laser processing conditions close to the ones used to melt the metal powders in the precur- sor layer. When this happens, the precursor layer gets ejected from the graphite surface while a localized expanding plasma plume forms, with the resulting soot redepositing all over the inside of the processing chamber, thwarting all efforts to form surface coatings. Thus, in order to deposit coatings on graphite by laser melting, optimization of both precursor layer thickness and laser processing conditions is very critical. Furthermore, fully dense coatings can only be obtained by complete melting of the precursor material, which requires laser intensity adequate enough to only melt the precursor material without sublimating the underlying graphite substrate. Direct laser-graphite interaction is highly undesirable for depositing surface coatings on graphite substrates by any laser surfacing technique including LISI.

The titanium coating did not delaminate at all, the zirconium coating delaminated in a few locations (only seen in SEM micrographs), whereas the niobium coating fully delaminated as a single crackfree solid sheet during sample preparation for interface XRD analysis (as seen in Fig. 6B). The most plausible explanation for the delamination of these coatings is the accumulation of residual stresses at the carbide/graphite interface in addition to strong shear forces that they were subjected to during sample preparation. Indeed, adhesion and delamination behavior of $\mathrm{Nb}$ coatings on carbonbased materials is very well documented in literature. For example, Kolosov et al. deposited Nb coatings on glassy carbon by galvanostatic electrochemical deposition and found that the coating starts to delaminate as the coating thickness 
increases due to accumulation of excessive compressive residual stresses at the interface [34]. Delamination and cracks at the coating-graphite interface are undesirable as they deteriorate the coating performance especially in severe service conditions. A subsequent thermal treatment can improve the integrity of laser deposited surface coatings on graphite by enhancing carbide formation at the coating/graphite interface as well as promoting stress-relief of the coating. For example, Barzilai et al deposited 8-12 $\mu \mathrm{m}$ thick niobium coatings on graphite by RF magnetron sputtering and achieved 4-fold adhesion improvement by annealing at 1073$1773 \mathrm{~K}$ for $12-480$ minutes, which was attributed to enhanced carbide formation at the interface [33].

\section{CONCLUSIONS}

We demonstrated the feasibility of producing surface coatings on graphite plates by laser melting pre-placed metal powders using a continuous wave (CW) laser. Following conclusions can be drawn from the present study:

(1) Transition metal based fully-dense and crackfree surface coatings of titanium $(50 \mu \mathrm{m})$, zirconium $(100 \mu \mathrm{m})$, and niobium $(100 \mu \mathrm{m})$ were deposited on graphite plates by the laser induced surface improvement (LISI) approach.

(2) XRD analysis of the coating surface revealed the presence of titanium and titanium oxides for titanium coating, various zirconium oxides for zirconium coating, and niobium-rich carbides and niobium oxides in case of niobium coating.

(3) Interface $X R D$ analysis revealed the presence of titanium carbide for titanium coating, zirconium carbides and zirconium oxides for zirconium coating, and carbon-rich niobium carbides, niobium and niobium oxides for niobium coating.

(4) Delamination was observed in case of niobium and zirconium coatings, which was attributed to a combination of residual stresses and strong shear forces of the polishing wheel used for sample preparation.

(5) SIMS analysis performed on niobium coating confirmed the presence of binder elements only at the coating surface, which confirms that the binder added to the precursor mixture forms a thin layer of slag at the coating surface during processing.

\section{ACKNOWLEDGEMENTS}

This work was supported by the Tennessee Higher Education Commission through a grant to the Center for Laser Applications, University of Tennessee Space Institute, Tullahoma.

\section{REFERENCES}

[1] N.S. Gorbunov // Fiziko-Khimicheskaya Mekhanika Materialov 3 (1967) 682.

[2] Y.V. Dzyadikevich and V.E. Oliinik // Powder Metallurgy and Metal Ceramics 35 (1996) 150.

[3] D.D.L. Chung // Journal of Materials Science 37 (2002) 1475.

[4] J.-H. Kang, H.-M. Cha, J.-H. Lee, Y.-G. Jung, H.-S. Lee and V.K. Srivastava // Progress in Organic Coatings 61 (2008) 291.

[5] S. Kumar, S. Mondal, A. Kumar, A. Ranjan and N. Prasad // Coatings 7 (2017) 101.

[6] C. Malmstrom, R. Keen and L. Green // Journal of Applied Physics 22 (1951) 593.

[7] D.A. Schulz, P.H. Higgs and J.D. Cannon, Research and Development on Advanced Graphite Materials; Volume 34 OxidationResistance Coatings for Graphite (WADD 1963).

[8] J.M. Criscione, R.A. Mercuri, E.P. Schram, A.W. Smith and H.F. Volk, High temperature protective coatings for graphite, Report Number: ML TDR 64-173 Part I (Union Carbide Corporation, 1964).

[9] A.L. Burykina and T.M. Yevtushok, Coatings from refractory compounds on graphite, In: Seminar on Heat Resisting Coatings (Nauka, Leningrad-Moscow, 1967), p. 145.

[10] O. Yamamoto, K. Imai, T. Sasamoto and M. Inagaki // Journal of the European Ceramic Society 12 (1993) 435.

[11] H. Li, J.G. Li and J.L. Chen // Materials Science Forum 475-479 (2005) 1367.

[12] A. Wank, G. Reisel, B. Wielage, D. Chemnitz, L. Martinez, D. LimbachOberfrohna, T. Schnick and D. Kriftel,, In: Proc. International Thermal Spray Conference (Basel, Switzerland, 2005).

[13] J. Zhao, Q. Guo, J. Shi, G. Zhai, L. Liu // Surface and Coatings Technology 201 (2006) 1861.

[14] S. Motojima and H. Mizatani // Thin Solid Films 186 (1990) L17.

[15] D.J. Varacalle, L.B. Lundberg, H. Herman and G. Bancke // Surface and Coatings Technology 86 (1996) 70.

[16] N.N. Rammo, H.R. Al-Amery, T. Abdul-Jabbar and H.I. Jaffer // Surface and Coatings Technology 203 (2009) 2891. 
[17] G.S. Cho and K.H. Choe // Surface and Coatings Technology 209 (2012) 131.

[18] S. Barzilai, M. Weiss, N. Frage and A. Raveh // Surface and Coatings Technology 197 (2005) 208.

[19] F. Brossa, E. Franconi and P. Schiller // Journal of Nuclear Materials 191-194 (1992) 469.

[20] B. Miles and J. Kerr, In: Proc. 32nd Joint Propulsion Conference and Exhibit (American Institute of Aeronautics and Astronautics, 1996).

[21] X. Yin, I. Gotman, L. Klinger and E.Y. Gutmanas // Materials Science and Engineering A 396 (2005) 107.

[22] I.A. Podchernyaeva, A.D. Panasyuk, O.N. Grigoriev, G.A. Frolov, A.M. Bloshchanevich, D.V. Yurechko and M.A. Vasil'kovskaya // Powder Metallurgy and Metal Ceramics 53 (2015) 688.

[23] I.A. Podchernyaeva, O.N. Grigor'ev, A.D. Panasyuk and D.V. Yurechko // Journal of Superhard Materials 38 (2016) 327.

[24] I.A. Podchernyaeva, O.N. Grigor'ev, D.V. Yurechko, A.M. Bloshchanevich and M.A.
Vasil'kovskaya // Powder Metallurgy and Metal Ceramics 54 (2016) 679.

[25] R. Vilar // Journal of Laser Applications 11 (1999) 64.

[26] R. Vilar // Materials Science Forum 301 (1999) 229.

[27] A. Agarwal and N.B. Dahotre // International Journal of Refractory Metals and Hard Materials 17 (1999) 283.

[28] L. Costa and R. Vilar // Rapid Prototyping Journal 15 (2009) 264.

[29] L. Costa, K. Lansford, D. Rajput and W. Hofmeister // Surface and Coatings Technology 203 (2009) 1984.

[30] N. Eustathopoulos // Metals 5 (2015) 350.

[31] A. Cottrell, Chemical Bonding in Transition Metal Carbides (The Institute of Materials, 1995).

[32] D. Rajput, K. Lansford, L. Costa and W. Hofmeister // Surface and Coatings Technology 203 (2009) 1281.

[33] S. Barzilai, N. Frage and A. Raveh // Surface and Coatings Technology 200 (2006) 4646.

[34] V.N. Kolosov and A.A. Shevyrev // The Physics of Metals and Metallography 117 (2016) 22. 